\title{
INTERNATIONAL LABOUR MARKET REGULATION AND ECONOMIC GROWTH WITH CREATIVE DESTRUCTION
}

\author{
TAPIO PALOKANGAS
}

CESIFO WORKING PAPER NO. 768

CATEGORY 4: LABOUR MARKETS

August 2002

\footnotetext{
An electronic version of the paper may be downloaded

- from the SSRN website: www.SSRN.com

- from the CESifo website: www.CESifo.de
} 


\title{
INTERNATIONAL LABOUR MARKET REGULATION AND ECONOMIC GROWTH WITH CREATIVE DESTRUCTION
}

\begin{abstract}
A multi-country Schumpeterian growth model is constructed when there is worldwide externality in technological knowledge. Households can enter the labour force as workers or become engineers at some cost. Production employs both workers and engineers while R\&D uses only engineers. Workers are unionized and labour market regulation supports union power in wage bargaining. It is shown that international coordination of labour market policy increases the growth rate and the level of welfare. When the interest-rate elasticity of consumption in the world is low (high), the simultaneous regulation (deregulation) of the labour market in all countries increases welfare.
\end{abstract}

JEL Classification: O40, J50, F02.

Keywords: international technology transfers, labour market regulation, endogenous growth.

\author{
Tapio Palokangas \\ Department of Economics \\ P.O.Box 54 \\ FIN-00014 University of Helsinki \\ Finland \\ Tapio.Palokangas@Helsinki.FI
}

The author thanks Paul Segerstrom, Klaus Wälde and other participants in the seventh international conference on Dynamics, Economic Growth and International Trade (DEGIT), Cologne, Germany, May 24-25, 2002, for useful comments. Financial support from the Yrjö Jahnsson Foundation is gratefully acknowledged. The author is responsible for any possible remaining errors. The author is also grateful to Center for Economic Studies in Munich for hospitality during his visit in July 2002. In that time, the final version of this paper was written. 


\section{Introduction}

Labour market regulation (deregulation) - i.e. the strengthening (weakening) of the workers' position in wage bargaining - may have strong effects on the level of employment, the growth rate and the level of welfare. This leads to the following problems. To what extent should a single country, which is dependent of technological knowledge in the other countries, regulate its labour market? Should labour market policy be internationally coordinated or should the countries be left alone to compete with each other by labour market deregulation? Should, for instance, the European Union be given a greater importance in labour market policy or should this be left for the national governments? This study tries to answer these questions.

In Jerger (2002), regulation and social standards are endogenously determined by politicians who have to solve a trade-off between equity and efficiency and whose utility is a quadratic function of some macroeconomic variables. In contrast, this study ignores such trade-off by assuming that the households in a country are similar and the government maximizes a household's welfare. It is shown that when technological change is properly incorporated into the model, efficiency can alone explain why a rational and benevolent government exercises labour market regulation.

Grossman and Helpman (1991) (in ch. 4), Aghion and Howitt (1998), and Wälde (1999) examine economic growth from the viewpoint of creative destruction in which firms can step forward in the quality ladders of technology by investment on $R \& D$. The study takes here a similar 'Schumpeterian' approach, but instead of a competitive labour market it assumes that unions and employers bargain over wages. The wages are then determined by a two-player game in which the parties are long-sighted enough to observe the effect of wages on the firms' investment policy.

Palokangas (1996, 2000) introduces collective bargaining into Romer's (1990) product-variety model with two labour inputs, skilled and unskilled workers, and obtains the following results. Higher bargaining power for unions leads to higher wages for unskilled workers, higher unemployment for both skilled and unskilled workers in production, a lower wage for skilled workers, a larger amount of $R \& D$ which uses skilled labour, and a higher growth rate. If the unions are not initially too strong, this increase in the 
growth rate is welfare enhancing. The product-variety models, however, ignore the uncertainty that is embodied in technological change. To eliminate this shortcoming, the study uses a model of creative destruction.

In the model, there is a fixed number $J$ of countries that are interdependent through international technology transfer. Each country $j$ contains a fixed number $\kappa$ of households. ${ }^{1}$ All households are modelled as dynastic families whose size remains unchanged over time. They are risk averters, share identical preferences and supply two labour inputs: workers, who are employed only in production, and engineers, who are employed in both production and $R \& D$. Family-optimization considerations determine the evolution of consumption expenditure over time, the allocation of savings across shares in different firms, and the decision whether to become engineers or enter the labour force as workers. A single family takes prices, wages, profits, the level of employment and aggregate labour supply as given.

Research firms can adopt ideas from each other. A single firm has technology which is a random variable but the probability of an improvement of its technology in one unit of time is an increasing function of both its and the other firms' $R \& D$. To focus on this technological transfer as the main connection between countries, this study assumes that there is no international trade in goods or factors and each intermediate product is specific to the country in which it is used and produced. ${ }^{2}$ Given this assumption, each country can have a separate stochastic process that characterizes its technological change and the growth rates can differ across the countries.

The structure of a single country can be characterized as follows:

(i) A large number of competitive firms produces final goods from the intermediate good and some indivisible factor of production. ${ }^{3}$

(ii) One monopolist at a time produces the intermediate good by workers and engineers. Several firms do $R \& D$ by using engineers and finance their expenditure by issuing shares. As soon as any of these firms

\footnotetext{
${ }^{1}$ It is necessary for the analysis that each country contains a large but finite number of households. The model would be a bit more complicated but the results still the same if the number of households differed across the countries.

${ }^{2}$ Howitt (2000) makes the same assumption for the same reason.

${ }^{3}$ It is assumed, for simplicity, only one intermediate good for each country. With some complication, the same results can be derived even with many intermediate goods.
} 
completes a new innovation, it takes over the whole production of the intermediate good and drives the old producer out of the market.

(iii) The households decide on their labour supply before entering the labour market. They save in shares in research firms of their own countries.

(iv) All workers are unionized. ${ }^{4}$ The labour union, which maximizes the discounted value of the flow of the workers' wage bill, and the employer federation, which maximizes the discounted value of the flow of the employers' profit, bargain over the workers' wages. The labour union has also the option to refuse from bargaining, in which case the workers' wage is competitively determined.

(v) The government determines the relative bargaining power of the labour union by its labour market policy. When the policy measures increase (decrease) the labour union's relative bargaining power, we say that the labour market is regulated (deregulated).

Section 3 considers households deciding on consumption and saving. This is a problem of stochastic dynamic programming and leads to the savings and investment functions for the countries. The study focuses entirely on the households' stationary equilibrium in which the allocation of resources is invariable across technologies, and ignores the behaviour of the system during the transitional period before the equilibrium is reached. Section 4 examines collective bargaining in the households' stationary state. Finally, section 5 considers the national governments which act as Stackelberg leaders with respect to the other agents. Two cases are examined: either the governments play Nash among themselves or they cooperate in labour market policy.

\footnotetext{
${ }^{4}$ This study assumes that the engineers are not unionized, for simplicity. In the larger version of this paper [Palokangas (2002)], both workers and engineers belong to the same union. Then, in line with Palokangas (1996) and (2000), it is shown that because a higher employment for engineers yields higher profits and higher labour income, the union and the employer will always make such wage contracts that the engineers will be fully employed. Given the full employment of engineers, the other results are the same as in this study.
} 


\section{Firms}

(a) Final-good producers. The representative final-good firm in country $j$ makes output $y_{j}$ from some indivisible factor of production and intermediate input $x_{j}$ through a Cobb-Douglas function

$$
y_{j}=B_{j} x_{j}^{1-\beta} /(1-\beta) \text { with } 0<\beta<1,
$$

where $B_{j}$ is the productivity parameter and $\beta$ a constant. It maximizes profit

$$
\Pi_{j} \doteq P_{j} y_{j}-p_{j} x_{j}=P_{j} B_{j} x_{j}^{1-\beta} /(1-\beta)-p_{j} x_{j}
$$

by intermediate input $x_{j}$, taking the input price $p_{j}$ and the output price $P_{j}$ as fixed. This implies the inverse demand function for input $x_{j}$,

$$
p_{j}=P_{j} B_{j} x_{j}^{-\beta}
$$

(b) Intermediate-good producers. Input $x_{j}$ is produced through technology

$$
x_{j}=X\left(m_{j}, n_{j}\right), \quad X_{m} \doteq \partial X / \partial m_{j}>0, \quad X_{n} \doteq \partial X / \partial n_{j}>0,
$$

where $m_{j}\left(n_{j}\right)$ is the demand for engineers (workers) in production. Assuming that technology (4) is of $C E S$ form, the unit cost $\psi_{j}$ is determined by

$$
\psi_{j}=\Psi\left(w_{j}, v_{j}\right) \doteq\left[\delta w_{j}^{1-\varepsilon}+(1-\delta) v_{j}^{1-\varepsilon}\right]^{1 /(1-\varepsilon)}, 0<\delta<1, \quad 0<\varepsilon<1,
$$

where $w_{j}\left(v_{j}\right)$ is the wage for engineers (workers), $\varepsilon$ the constant elasticity of substitution, and $\delta$ the constant relative weight of engineers. Assumption $\varepsilon<1$ is the Inada condition for $C E S$ technology: there cannot be output without both of the inputs. By duality, the following conditions must hold:

$$
\begin{aligned}
& m_{j}=\frac{\partial \Psi}{\partial w_{j}} x_{j}=\delta\left(\frac{\psi_{j}}{w_{j}}\right)^{\varepsilon} x_{j}, \quad n_{j}=\frac{\partial \Psi}{\partial v_{j}} x_{j}=(1-\delta)\left(\frac{\psi_{j}}{v_{j}}\right)^{\varepsilon} x_{j}, \\
& X_{m} / X_{n}=w_{j} / v_{j}, \quad x_{j}=X_{m} m_{j}+X_{n} n_{j} .
\end{aligned}
$$

Given the demand function (3), the producer maximizes its profit

$$
\pi_{j} \doteq p_{j} x_{j}-\psi_{j} x_{j}=P_{j} B_{j} x_{j}^{1-\beta}-\psi_{j} x_{j}=P_{j} B_{j} x_{j}^{1-\beta}-\psi_{j} x_{j}
$$


by its output $x_{j}$, taking its unit cost $\psi_{j}$ and the price for the final good, $P_{j}$, as fixed. Given (2)-(7), this yields

$$
\psi_{j}=(1-\beta) P_{j} B_{j} x_{j}^{-\beta}, \quad \frac{\pi_{j}}{\psi_{j} x_{j}}=\frac{\beta}{1-\beta}, \quad \frac{\Pi_{j}}{\psi_{j} x_{j}}=\frac{\beta}{(1-\beta)^{2}} .
$$

(c) Research firms. Because only engineers are used in $R \& D$, investment expenditure in country $j$ is equal to labour cost $w_{j} l_{j}$, where $l_{j}$ is the engineers' labour input in $R \& D$. When a research firm in country $j$ is successful, it uses its new technology to drive the old producer out and starts producing good $j$ itself. Its profits are then distributed among those who had financed it. When $R \& D$ is not successful for a firm, there is no profit and the ex post value of a share of the firm is zero.

Country $j$ is subject to technological change which is characterized by a Poisson process $q_{j}$ as follows. During a short time interval $d t$, there is an innovation $d q_{j}=1$ with probability $\Lambda_{j} d t$, and no innovation $d q_{j}=0$ with probability $1-\Lambda_{j} d t$, where $\Lambda_{j}$ is the arrival rate of innovations in the research process. It is assumed that the arrival rate $\Lambda_{j}$ is in fixed proportion $\lambda$ to a Cobb-Douglas function $Z_{j}$ of research input in the country $j, l_{j}$, and the average research input in the rest of the world, $l_{-j}$ :

$$
\begin{aligned}
& \Lambda_{j}=\lambda Z_{j}\left(l_{j}, l_{-j}, \mu\right) \text { with } Z_{j}\left(l_{j}, l_{-j}, \mu\right) \doteq l_{j}^{1-\mu} l_{-j}^{\mu}, \quad l_{-j} \doteq \frac{1}{J-1} \sum_{k \neq j} l_{k}, \\
& 0<\mu<1, \quad \partial Z_{j} / \partial \mu=0 \text { and } \partial^{2} Z_{j} /\left(\partial l_{j} \partial \mu\right)=-1<0 \text { for } l_{j}=l_{-j}
\end{aligned}
$$

The higher parameter $\mu$ is, the more the countries are technologically dependent on each other. Each new generation of products provides exactly $\gamma>1$ times as many services as the product of the generation before it. Hence, the level of productivity $B_{j}$ is determined by the currently most advanced technology $t$. The invention of a new technology raises $t$ by one and the level of productivity by $\gamma>1$, so that

$$
B_{j}^{t}=B_{j}^{0} \gamma^{t}
$$

Because $\ln B_{j}^{t+1}-\ln B_{j}^{t}=(\ln \gamma) \chi(t)$, where $\chi(t)$ is the number of innovations between $t$ and $t+1$, and $\chi(t)$ is Poisson distributed with parameter $\lambda Z_{j}$, the average growth rate of the level of productivity $B_{j}$ in the stationary state is in fixed proportion to $Z_{j}$ as $E\left[\log B_{j}^{t+1}-\log B_{j}^{t}\right]=\lambda Z_{j} \log \gamma$, 
where $E$ is the expectation operator. ${ }^{5}$ This result shows that research inputs $Z_{j} \doteq l_{j}^{1-\mu} l_{-j}^{\mu}$ can be used as proxies of the average growth rates of the countries $j \in\{1, \ldots, J\}$.

\section{Households}

Households make two choices separately: $(a)$ they decide their occupation on the basis of prospective income; and $(b)$ they determine the flow of savings given the flow of income. The outcome of these choices are as follows.

(a) Labour supply. Because each family can change its members' occupation from a worker to an engineer at some cost and the abilities of all individuals in country $j$ differ, we can introduce a decreasing and convex transformation function between the number of workers, $N_{j}$, and the number of engineers, $L_{j}$, as follows:

$$
N_{j}=N\left(L_{j}\right), \quad N^{\prime}<0, \quad N^{\prime \prime}<0 .
$$

More and more workers must be transformed in order to create one more engineering input. Engineers are always fully employed. Because the workers are used only in production, their full employment constraint is given by

$$
n_{j} \leq N_{j}=N\left(L_{j}\right)
$$

where $n_{j}$ is the level of employment and $N_{j}$ the labour supply. A worker's expected wage $v_{j}^{e} \doteq v_{j} n_{j} / N_{j}$ is equal to the wage $v_{j}$ times the probability of employment, $n_{j} / N_{j}$. Since the supply of the engineers is always equal to the demand for them, $L_{j}=l_{j}+m_{j}$, their expected wage is the wage $w_{j}$.

Because households must choose their combination of labour supply before entering the labour market, this choice is based on the transformation function (11) and the expected wages $\left(w_{j}, v_{j}^{e}\right)$, which the household takes as given. This equilibrium is found by maximizing expected income $w_{j} L_{j}+v_{j}^{e} N_{j}=w_{j} L_{j}+v_{j}^{e} N\left(L_{j}\right)$ by $L_{j}$, which yields the first order condition $w_{j} / v_{j}^{e}=-N^{\prime}\left(L_{j}\right)$. This, (11) and definition $v_{j}^{e} \doteq v_{j} n_{j} / N_{j}$, yield

$$
-\frac{N^{\prime}\left(l_{j}+m_{j}\right)}{N\left(l_{j}+m_{j}\right)}=-\frac{N^{\prime}\left(L_{j}\right)}{N\left(L_{j}\right)}=\frac{w_{j}}{v_{j}^{e} N_{j}}=\frac{w_{j}}{v_{j} n_{j}} .
$$

\footnotetext{
${ }^{5}$ For this, see Aghion and Howitt (1998), p. 59.
} 
(b) Saving. The utility for household $\iota \in\{1, \ldots, \kappa\}$ in country $j$ from an infinite stream of consumption beginning at time $\tau$ takes the form

$$
U\left(C_{j \iota}, \tau\right)=E \int_{\tau}^{\infty} C_{j \iota}^{\sigma} e^{-\rho(\theta-\tau)} d \theta \text { with } 0<\sigma<1 \text { and } \rho>0,
$$

where $\theta$ is time, $E$ the expectation operator, $C_{j \iota}$ the index of consumption, $\rho$ the rate of time preference and $1 /(1-\sigma)$ is the constant relative risk aversion. Aggregate expenditure in the whole world is used as the numeraire:

$$
\sum_{j=1}^{J} \sum_{\iota=1}^{\kappa} P_{j} C_{j \iota}=\sum_{j=1}^{J} P_{j} \sum_{\iota=1}^{\kappa} C_{j \iota}=1
$$

where $P_{j}$ is the price for the final good in country $j$.

When household $\iota$ has financed a successful $R \& D$ project, it acquires the right to a certain share of profits the successful firm earns in the production of final goods. Since the old producer is driven out of the market, all shares held in it lose their value. Let $s_{j \iota}$ be the true profit share of household $\iota$ when the uncertainty of the outcome of the projects are taken into account. Following Wälde (1999), we assume that the change in this share, $d s_{j \iota}$, is a function of the increment $d q_{j}$ of a Poisson process $q_{j}$ as follows:

$$
d s_{j \iota}=\left(i_{j \iota}-s_{j \iota}\right) d q_{j} \text { with } i_{j \iota} \doteq S_{j \iota} /\left(w_{j} l_{j}\right),
$$

where $S_{j}$ is saving by household $\iota$ in country $j$. When a household does not invest in the upcoming vintage, her share holdings are reduced to zero in the case of research success $d q_{j}=1$. If it invests, then the amount of share holdings depends on its relative investment in the vintage.

Total labour income in country $j, I_{j}$ is equal to labour expenditure in production, $\psi_{j} x_{j}$, and in $R \& D, w_{j} l_{j}$,

$$
I_{j} \doteq w_{j} l_{j}+\psi_{j} x_{j}
$$

The total income of household $\iota$ in country $j, A_{j \iota}$, consists of an equal share $1 / \kappa$ of both labour income $I_{j}$ and the profit of the final-good firm, $\Pi_{j}$, and the share $s_{j \iota}$ of the total profits of the intermediate-good firm, $\pi_{j}$,

$$
A_{j \iota} \doteq\left(I_{j}+\Pi_{j}\right) / \kappa+s_{j} \pi_{j}=\left(w_{j} l_{j}+\psi_{j} x_{j}+\Pi_{j}\right) / \kappa+s_{j \iota} \pi_{j} .
$$


The budget constraint of household $\iota$ in country $j$ is given by

$$
A_{j \iota}=P_{j} C_{j \iota}+S_{j \iota}
$$

where $C_{j \iota}$ is consumption and $P_{j}$ the consumption price. Household $\iota$ chooses its saving $S_{j \iota}$ and takes labour income $I_{j}$, profits $\Pi_{j}$ and $\pi_{j}$, investment expenditure $w_{j} l_{j}$ and aggregate research input $Z_{j}$ as given.

(c) Optimization. We denote the value of receiving a share $s_{j \iota}$ of the profits of the monopolists using current technology $t$ by $\Omega\left(s_{j \iota}, t\right)$, and the value of receiving a share $i_{j \iota}$ of the profits of the monopolists of the next generation by $\Omega\left(i_{j \iota}, t+1\right)$. Household $\iota$ maximizes its utility (14) subject to stochastic process (16) and the budget constraint (19) by its saving $S_{j \iota}$, given $I_{j}, \Pi_{j}$, $\pi_{j}, w_{j} l_{j}$ and $Z_{j}$. This maximization leads to the Bellman equation ${ }^{6}$

$$
\rho \Omega\left(s_{j \iota}, t\right)=\max _{S_{j \iota}}\left\{C_{j \iota}^{\sigma}+\Lambda_{j}\left[\Omega\left(i_{j \iota}, t+1\right)-\Omega\left(s_{j \iota}, t\right)\right]\right\},
$$

where $C_{j \iota}=\left(A_{j \iota}-S_{j \iota}\right) / P_{j}$ and $\Lambda_{j}=\lambda Z_{j}=\lambda l_{j}^{1-\mu} l_{-j}^{\mu}$ by (9) and (19). The first order condition associated with the Bellman equation (20) is

$$
\lambda Z_{j} \frac{d}{d S_{j \iota}}\left[\Omega\left(i_{j \iota}, t+1\right)-\Omega\left(s_{j \iota}, t\right)\right]=\sigma C_{j \iota}^{\sigma-1} / P_{j} .
$$

We try the solution that consumption expenditure $P_{j} C_{j \iota}$ is a share $0 \leq 1 / h_{j \iota} \leq 1$ out of income $A_{j \iota}$, and that the value function is of the form $\Omega=\left(A_{j \iota} / h_{j \iota}\right)^{\sigma} / r_{j \iota}$, where the income-consumption ratio $h_{j \iota}$ and the (subjective) interest rate $r_{j \iota}$ are independent of income $A_{j \iota}$. Inserting these guesses into (20) and (21), it is shown in Appendix $A$ that the interest rate $r_{j}$ and the ratio of the labour costs in the two sectors for country $j$ are given by ${ }^{7}$

$$
\begin{aligned}
& r_{j \iota}=r_{j} \doteq \rho+\left(1-\gamma^{\sigma}\right) \lambda Z_{j}, \\
& w_{j} l_{j} /\left(\psi_{j} x_{j}\right)=\varpi\left[h\left(Z_{j}\right)-1\right], \quad h^{\prime}>0 \text { and } \varpi>0 \text { constant. }
\end{aligned}
$$

\section{Employment and wage bargaining}

In the system of six differentiable equations (4), (5), (6), (13) and (23), there are six endogenous variables - the unit cost $\psi_{j}$, the engineers' and workers'

\footnotetext{
${ }^{6}$ Cf. Dixit and Pindyck (1994).

${ }^{7}$ Note that this definition of the interest rate $r_{j}$ contains also the expected growth of consumption through technological change (10).
} 
wages, $w_{j}$ and $v_{j}$, the intermediate input $x_{j}$ and the employment of engineers and workers in production, $m_{j}$ and $n_{j}$ - and two exogenous variables - the employment of engineers in $R \& D, l_{j}$, and the level of $R \& D, Z_{j}$. This system defines the following differentiable functions (see Appendix $B$ ):

$$
\begin{aligned}
& w_{j}=w\left(l_{j}, Z_{j}\right), \quad v_{j}=v\left(l_{j}, Z_{j}\right), \quad m_{j}=m\left(l_{j}, Z_{j}\right), \quad n_{j}=n\left(l_{j}, Z_{j}\right), \\
& x_{j}=x\left(l_{j}, Z_{j}\right), \quad \partial x_{j} / \partial l_{j}<0 .
\end{aligned}
$$

Result $\partial x_{j} / \partial l_{j}<0$ means that the increase of resources in $R \& D$ (i.e., a higher $l_{j}$ ) deprives resources from production and yields lower output $x_{j}$. Given functions (24), the full employment constraint (12) takes the form

$$
N\left(l_{j}+m\left(l_{j}, Z_{j}\right)\right) \geq n\left(l_{j}, Z_{j}\right)
$$

In each country $j$, the workers' wage $v_{j}$ is determined by collective bargaining between labour union $j$, which represents the workers, and employer federation $j$, which represents firms that employ workers. It is assumed, for simplicity, that these both are risk neutral and have the same rate of time preference $\varrho>0$. Union $j$ attempts then to maximize the expected value of the stream of the workers' real wage bill $v_{j} n_{j} / P_{j}, \mathcal{U}_{j}$, while employer federation $j$ attempts to maximize the expected value of the stream of real profits $\pi_{j} / P_{j}, \mathcal{F}_{j} .{ }^{8}$ Given the stochastic technological progress explained in part $(c)$ of section 2 , these targets take the form: ${ }^{9}$

$$
\begin{aligned}
& \mathcal{U}_{j}\left(l_{j}, l_{-j}, \alpha_{j}, \mu\right) \doteq E \int_{0}^{\infty} e^{-\varrho \theta}\left(\frac{v_{j} n_{j}}{P_{j}}\right) d \theta=\left(\frac{B_{j}^{0} v_{j} n_{j}}{B_{j} P_{j}}\right) \frac{1}{\varrho+(1-\gamma) \lambda Z_{j}} \\
& \mathcal{F}_{j}\left(l_{j}, l_{-j}, \alpha_{j}, \mu\right) \doteq E \int_{0}^{\infty} e^{-\varrho \theta}\left(\frac{\pi_{j}}{P_{j}}\right) d \theta=\left(\frac{B_{j}^{0} \pi_{j}}{B_{j} P_{j}}\right) \frac{1}{\varrho+(1-\gamma) \lambda Z_{j}} .
\end{aligned}
$$

Union $j$ has always the possibility of refusing from collective bargaining in which case the workers' wage $v_{j}$ is determined by supply and demand and there is full employment. That is why union $j$ cannot make an agreement that

\footnotetext{
${ }^{8}$ Because the workers and the employers consume the final good, their real income is defined by the final-good price $P_{j}$. If the employer federation represented also the finalgoods firms, then it would maximize the discounted value of the stream of the real profits $\left(\pi_{j}+\Pi_{j}\right) / P_{j}$ of both the intermediate and final-goods firms rather than the discounted value of the stream of $\pi_{j} / P_{j}$. However, because in the model $\Pi_{j}$ is in fixed proportion to $\pi_{j}$, the results were the same.

${ }^{9}$ For this, see e.g. Aghion and Howitt (1998), p. 61.
} 
produces a lower welfare for its members than in full employment. Denoting the level of employment corresponding to full employment $n_{j}=N_{j}$ by $l_{j}^{f}$ and noting (26), this incentive constraint can be written as follows:

$$
\mathcal{U}_{j}\left(l_{j}, l_{-j}, \alpha_{j}, \mu\right) \geq \mathcal{U}_{j}\left(l_{j}^{f}, l_{-j}, \alpha_{j}, \mu\right) .
$$

In bargaining, union $j$ (employer federation $j$ ) maximizes its welfare $\mathcal{U}_{j}$ $\left(\mathcal{F}_{j}\right)$ by the workers' wage $v_{j}$ subject to the employment constraints $(25)$ and the union's incentive constraint (27), taking the number of engineers devoted to $R \& D$ elsewhere, $l_{-j}$, as given. Because there is one-to-one correspondence from $v_{j}$ to $l_{j}$ through (24), in the model $v_{j}$ can be replaced by $l_{j}$ as the instrument of bargaining. The outcome of bargaining is then obtained through the maximization of the Generalized Nash Product of the parties' targets, $\mathcal{U}_{j}^{\alpha} \mathcal{F}_{j}^{1-\alpha}$, where constant $0<\alpha<1$ is the union's relative bargaining power, by $l_{j}$, subject to $(25)$ and (27), taking $l_{-j}$ as given. This maximization yields the following results (Appendix $C$ ):

Proposition 1 (i) With unemployment for the workers, $N_{j}>n_{j}$, the employment of engineers in $R \& D, l_{j}$, is above its level $l_{j}^{f}\left(l_{-j}, \mu\right)$ that corresponds to the workers' full employment $N_{j}=n_{j}$.

(ii) When the number of engineers in $R \& D$ elsewhere in the world, $l_{-j}$, is held constant, labour market regulation in country $j$ (i.e., a higher $\alpha_{j}$ ) fosters $R \& D$ and growth in that country, $\partial l_{j} / \partial \alpha_{j}>0$.

(iii) Simultaneous labour market regulation in all countries (i.e., a higher $\alpha_{j}=\alpha$ for all $j$ ) increases the world growth rate $l_{j}=l_{-j}=Z_{j}=Z$.

These result are explained in the final section.

\section{$5 \quad$ The governments}

Because country $j$ consumes its output, $y_{j}=\sum_{\iota=1}^{\kappa} C_{j \iota}$ obtains. Given the symmetry across the households in country $j$, this takes the form $C_{j \iota}=y_{j} / \kappa$. A household's consumption $C_{j \iota}$ relative to the level of productivity, $\gamma^{t}$, is given by $c_{j} \doteq \gamma^{-t} C_{j \iota}$. This, $C_{j \iota}=y_{j} / \kappa,(1),(10)$ and (24) produce

$$
\begin{aligned}
& c_{j}\left(l_{j}, Z_{j}\right) \doteq \gamma^{-t} C_{j \iota}=\gamma^{-t} y_{j} / \kappa=\gamma^{-t} B_{j} x_{j}^{1-\beta} /[(1-\beta) \kappa] \\
& =B_{j}^{0} x\left(l_{j}, Z_{j}\right)^{1-\beta} /[(1-\beta) \kappa] \text { with } \partial c_{j} / \partial l_{j}<0 .
\end{aligned}
$$


Noting (28), the utility function (14) takes the form

$$
U\left(C_{j \iota}, \tau\right)=E \int_{\tau}^{\infty} c_{j}\left(l_{j}, Z_{j}\right)^{\sigma} \gamma^{\sigma} e^{-\rho(\theta-\tau)} d \theta
$$

According to proposition $1(i)$, the full employment constraint takes the form $l_{j} \geq l_{j}^{f}\left(l_{-j}, \mu\right)$. Given proposition $1(i i)$, the government in country $j$ (hereafter government $j$ ) can increase (decrease) the number of engineers in $R \& D, l_{j}$, by labour market regulation (deregulation). If the government is benevolent, it maximizes social welfare $(29)$ by $l_{j}$ subject to $l_{j} \geq l_{j}^{f}\left(l_{-j}, \mu\right)$, given the number of engineers devoted to $R \& D$ elsewhere, $l_{-j}$. Denoting the value of the state of technology $t$ for government $j$ by $\Upsilon_{j}(t)$, the Bellman equation for the government's optimization can be written as follows:

$$
\begin{aligned}
& \rho \Upsilon_{j}(t)=\max _{l_{j} \geq l_{j}^{f}\left(l_{-j}, \mu\right)} \mathcal{B}_{j}, \quad \text { where } \\
& \mathcal{B}_{j} \doteq c_{j}\left(l_{j}, Z_{j}\left(l_{j}, l_{-j}, \mu\right)\right)^{\sigma} \gamma^{\sigma t}+\lambda Z_{j}\left(l_{j}, l_{-j}, \mu\right)\left[\Upsilon_{j}(t+1)-\Upsilon_{j}(t)\right] .
\end{aligned}
$$

Noting (9) and (30), we obtain the partial derivative of $\mathcal{B}_{j}$ as follows:

$$
\frac{\partial \mathcal{B}_{j}}{\partial l_{j}}=\sigma c_{j}^{\sigma-1} \gamma^{\sigma t}\left[\frac{\partial c_{j}}{\partial l_{j}}+\frac{\partial c_{j}}{\partial Z_{j}} \frac{\partial Z_{j}}{\partial l_{j}}\right]+\lambda\left[\Upsilon_{j}(t+1)-\Upsilon_{j}(t)\right] \frac{\partial Z_{j}}{\partial l_{j}} .
$$

We try the solution that the value function is of the form $\Upsilon_{j}(t)=\vartheta c_{j}^{\sigma} \gamma^{\sigma t}$, where $\vartheta$ is independent of the endogenous variables of the system. In Appendix $D$, this solution yields the following proposition:

Proposition 2 (i) If labour market regulation is carried out at the level of single country and the dependence on the rest of the world increases (i.e., $\mu$ rises), then the employment of engineers in $R \& D$ falls, $d l_{j} / d \mu<0$. (ii) If the elasticity of consumption with respect to the interest rate, $\eta \doteq$ $(r / c) d c / d r$, is smaller (greater) than $1 / \sigma$, where $1 /(1-\sigma)$ is a household's rate of risk aversion, then it is welfare enhancing to regulate (deregulate) the labour market simultaneously in all countries $j$.

A government faces a trade-off between rapid technological change and low income. When technological change in a country depends less on foreign $R \& D$ and more on domestic $R \& D$ (i.e, a higher $\mu$ ), it is more attractive 
for the government to speed up technological change through lower income and consequently, there will be more engineers in $R \& D$. In a stationary equilibrium the level of utility (14) takes the form $U_{j}=c_{j}^{\sigma} / r_{j}$. If the interest rate $r_{j}$ (as being a function of the growth rate $l_{j}$ ) is chosen to maximize utility $U_{j}$, the first-order condition $\partial U_{j} / \partial r_{j}=0$ implies $\eta \doteq\left(r_{j} / c_{j}\right) \partial c_{j} / \partial r_{j}=1 / \sigma$.

When labour market regulation is coordinated across countries $1, \ldots, J$, we obtain the Pareto optimum for the whole world. The governments then behave as if there were only one government in the world and $\mu \rightarrow 0$ holds. Because $\left.l_{j}\right|_{\mu=0}>\left.l_{j}\right|_{\mu>0}$ by proposition $2(i)$, there will be more engineers and consequently a higher growth rate $l_{j}=l_{-j}=Z_{j}=Z$ than with independent governments. From proposition $1(i i)$ it follows that to increase $l_{j}$ to the level corresponding to the Pareto optimum, each independent government $j$ should increase its $\alpha_{j}$. Hence, the following corollary is established:

Proposition 3 The international coordination of labour market policy speeds up economic growth (i.e., increases Z). Independent national governments tend to overly deregulate their labour markets (i.e., to choose too low $\alpha_{j}$ ).

This result is explained in the final section.

\section{Conclusions}

This paper examined a world that has the following properties. First, growth is generated by creative destruction: a firm creating the newest technology by a successful $R \& D$ project crowds out the other firms with older technologies from the market so that the latter lose their value. Second, wages are determined by collective bargaining. Third, the firms finance their $R \& D$ by selling shares, and the households save only by buying these shares. Fourth, the households choose optimally their supply two primary inputs: engineers which are used both in production and $R \& D$; and workers which are employed only in production. The main findings of the paper were as follows.

Labour market deregulation, which weakens the unions and increases the employment of the workers, slows down economic growth in two ways. First, with lower unemployment for the workers, the households will more likely to remain workers and less likely to become engineers. Second, because the two 
labour inputs are complements in production, a higher level of employment for the workers increases also the demand for engineers in the production sector. Since the former effect reduces the supply of engineers and the latter transfers these from $R \& D$ into production, the number of engineers devoted to $R \& D$ will fall. With a lower level of $R \& D$, there will be less innovations and the growth rate will fall. Correspondingly, it can be shown that labour market regulation, which strengthens the unions and decreases the employment of the workers, speeds up growth. From these results it follows that if the growth rate is above (below) the optimal growth rate of the economy, then the labour market should be deregulated (regulated).

If the countries regulate their labour markets independently, then increased dependence of countries slows down but international coordination of labour market policy speeds up economic growth. This is because a government faces a trade-off between rapid technological change and low current income. When technological change in a country depends more on foreign $R \& D$ and less on domestic $R \& D$, the trade-off becomes more restrictive and the government must slow down technological change through deregulation. With international coordination, the externality caused by the dependence of countries can be internalized. The trade-off then becomes less restrictive for the governments taken together, which means that these can speed up technological change through regulation. In other words, independent local governments will overly deregulate the labour market when compared to the case of international cooperation.

Finally, the world can be divided into regulation and deregulation regimes as follows. If the elasticity of consumption with respect to the interest rate is below (above) some critical level, then regulation (deregulation) that increases (decreases) the unions' bargaining power in the labour market is welfare enhancing. The interest rate is a function of the growth rate. Because in a stationary state the level of utility is equal to some function of consumption (which correspond instantaneous utility), divided by the interest rate, ${ }^{10}$ there exists utility-maximizing levels for the interest rate and the growth rate, at which the interest-elasticity of consumption is equal to the critical

\footnotetext{
${ }^{10}$ Because we have chosen the households' aggregate spending as the numeraire, current expenditure on consumption is equal to future expenditure. This means that utilities can be discounted by the interest rate.
} 
level. If the interest-elasticity of consumption is below the critical level, then the growth rate is above its utility-maximizing level and the labour markets should be deregulated to slow down growth.

While a great deal of caution should be exercised when a highly stylized growth model is used to draw conclusions about the effects of public policy, the following judgement nevertheless seems to be justified. With greater international externality in technological change, it is a good idea to increase international cooperation in labour market policy.

\section{Appendix A}

Let us denote variables depending on technology $t$ by superscript $t$. Since according to (18) income $A_{j \iota}^{t}$ depends directly on the share $s_{j \iota}^{t}$, we denote $A_{j \iota}^{t}\left(s_{j \iota}^{t}\right)$. Guessing that $h_{j \iota}$ is invariant across technologies, we obtain

$$
P_{j}^{t} C_{j \iota}^{t}=A_{j \iota}^{t}\left(s_{j \iota}^{t}\right) / h_{j \iota}, \quad S_{j \iota}^{t}=\left(1-1 / h_{j \iota}\right) A_{j \iota}^{t}\left(s_{j \iota}^{t}\right) .
$$

The share in the next producer $t+1$ is determined by investment under technology $t, s_{j \iota}^{t+1}=i_{j \iota}^{t}$. The value functions are then given by

$$
\Omega\left(s_{j \iota}^{t}, t\right)=\left(C_{j \iota}^{t}\right)^{\sigma} / r_{j \iota}, \quad \Omega\left(i_{j \iota}^{t}, t+1\right)=\left(C_{j \iota}^{t+1}\right)^{\sigma} / r_{j \iota} .
$$

Given this, we obtain

$$
\partial \Omega\left(s_{j \iota}^{t}, t\right) / \partial S_{j \iota}^{t}=0
$$

From (16), (18), (32) and (33) it follows that

$$
\begin{aligned}
& \frac{\partial i_{j \iota}^{t}}{\partial S_{j \iota}^{t}}=\frac{1}{w_{j}^{t} t j_{j}}, \quad \frac{\partial\left[A_{j \iota}^{t+1}\left(i_{j \iota}^{t}\right)\right]}{\partial i_{j \iota}^{t}}=\frac{\partial\left[A_{j \iota}^{t+1}\left(s_{j \iota}^{t+1}\right)\right]}{\partial s_{j \iota}^{t+1}}=\pi_{j}^{t+1}, \\
& \frac{\partial \Omega\left(i_{j \iota}^{t}, t+1\right)}{\partial S_{j \iota}^{t}}=\frac{\sigma}{r_{j \iota}}\left(C_{j \iota}^{t+1}\right)^{\sigma-1} \frac{\partial C_{j \iota}^{t+1}}{\partial A_{j \iota}^{t+1}} \frac{\partial A_{j \iota}^{t+1}}{\partial i_{j \iota}^{t}} \frac{\partial i_{j \iota}^{t}}{\partial S_{j \iota}^{t}}=\sigma \frac{\left(C_{j \iota}^{t+1}\right)^{\sigma-1} \pi_{j}^{t+1}}{r_{j \iota} h_{j \iota} P_{j}^{t+1} w_{j}^{t} l_{j}^{t}} .
\end{aligned}
$$

We focus on a stationary equilibrium where the allocation of labour, $\left(l_{j}^{t}, m_{j}^{t}, n_{j}^{t}, x_{j}^{t}\right)$ and a household's expenditure share, $C_{j \iota}^{t} / y_{j}^{t},{ }^{11}$ are invariant

\footnotetext{
${ }^{11}$ The domestic households consume the domestic output.
} 
across technologies. Given (5), (6), (8), (9), (18) and (32), this implies

$$
\begin{aligned}
& l_{j}^{t}=l_{j}, \quad n_{j}^{t}=n_{j}, \quad m_{j}^{t}=m_{j}, \quad x_{j}^{t}=x_{j}, \quad Z_{j}^{t}=Z_{j}, \quad \psi_{j}^{t}=\psi_{j}, \quad v_{j}^{t}=v_{j}, \\
& w_{j}^{t}=w_{j}, \quad \Pi_{j}^{t}=\Pi_{j}, \quad \pi_{j}^{t}=\pi_{j}, \quad P_{j}^{t} y_{j}^{t}=P_{j}^{t+1} y_{j}^{t+1}, \quad A_{j \iota}^{t}=A_{j \iota}, \quad S_{j \iota}^{t}=S_{j \iota}, \\
& C_{j \iota}^{t} / y_{j}^{t}=C_{j \iota}^{t+1} / y_{j}^{t+1},
\end{aligned}
$$

for all $j$. From (1), (10) and (36) it then follows that

$$
P_{j}^{t} / P_{j}^{t+1}=y_{j}^{t+1} / y_{j}^{t}=C_{j \iota}^{t+1} / C_{j \iota}^{t}=B_{j}^{t+1} / B_{j}^{t}=\gamma .
$$

Inserting (32), (33) and (37) into equation (20), we obtain

$$
\begin{aligned}
0 & =\left(\rho+\Lambda_{j}\right) \Omega\left(s_{j \iota}^{t}, t\right)-\left(C_{j \iota}^{t}\right)^{\sigma}-\Lambda_{j} \Omega\left(i_{j \iota}^{t}, t+1\right) \\
& =\left(\rho+\Lambda_{j}\right)\left(C_{j \iota}^{t}\right)^{\sigma} / r_{j \iota}-\left(C_{j \iota}^{t}\right)^{\sigma}-\Lambda_{j}\left(C_{j \iota}^{t+1}\right)^{\sigma} / r_{j} \\
& =\left(C_{j \iota}^{t}\right)^{\sigma}\left[\rho+\Lambda_{j}-r_{j \iota}-\gamma^{\sigma} \Lambda_{j}\right] / r_{j \iota}=\left(C_{j \iota}^{t}\right)^{\sigma}\left[\rho-r_{j \iota}+\left(1-\gamma^{\sigma}\right) \lambda Z_{j}\right] / r_{j \iota}
\end{aligned}
$$

This leads to the function

$$
r_{j}=r_{j \iota}=\rho+\left(1-\gamma^{\sigma}\right) \lambda Z_{j}
$$

Inserting (8) and (34)-(38) into (21) yields

$$
\begin{aligned}
0 & =\lambda Z_{j} \frac{\partial \Omega\left(i_{j \iota}^{t}, t+1\right)}{\partial S_{j \iota}^{t}}-\sigma \frac{\left(C_{j \iota}^{t}\right)^{\sigma-1}}{P_{j}^{t}}=\lambda Z_{j} \sigma \frac{\left(C_{j \iota}^{t+1}\right)^{\sigma-1} \pi_{j}}{r_{j} h_{j \iota} P_{j}^{t+1} w_{j} l_{j}}-\sigma \frac{\left(C_{j \iota}^{t}\right)^{\sigma-1}}{P_{j}^{t}} \\
& =\sigma \frac{\left(C_{j \iota}^{t}\right)^{\sigma-1}}{h_{j \iota} P_{j}^{t}}\left[\lambda Z_{j} \frac{\gamma^{\sigma} \pi_{j}}{r_{j} w_{j} l_{j}}-h_{j \iota}\right]=\sigma \frac{\left(C_{j \iota}^{t}\right)^{\sigma-1}}{h_{j \iota} P_{j}^{t}}\left[\frac{\beta \lambda \gamma^{\sigma}}{1-\beta} \frac{\psi_{j} x_{j}}{r_{j} w_{j} l_{j}} Z_{j}-h_{j \iota}\right]
\end{aligned}
$$

and

$$
h_{j \iota}=h_{j} \doteq \frac{\beta \lambda \gamma^{\sigma}}{1-\beta} \frac{\psi_{j} x_{j}}{r_{j} w_{j} l_{j}} Z_{j}
$$

Because the shares in domestic firms are the only assets for the households, in equilibrium $w_{j} l_{j}=\sum_{\iota=1}^{\kappa} S_{j \iota}$ must hold. This, $\sum_{\iota=1}^{\kappa} s_{j_{\iota}}=1$, (8), (18), (32) and (39) produce

$$
\frac{h_{j} w_{j} l_{j}}{h_{j}-1}=\frac{h_{j}}{h_{j}-1} \sum_{\iota=1}^{\kappa} S_{j \iota}=\sum_{\iota=1}^{\kappa} A_{j \iota}=w_{j} l_{j}+\psi_{j} x_{j}+\Pi_{j}+\pi_{j}
$$


and

$$
w_{j} l_{j} /\left(\psi_{j} x_{j}\right)=\left(h_{j}-1\right)\left(\psi_{j} x_{j}+\Pi_{j}+\pi_{j}\right) /\left(\psi_{j} x_{j}\right)=\varpi\left(h_{j}-1\right),
$$

where $\varpi \doteq 1+\beta /(1-\beta)+\beta /(1-\beta)^{2}>0$. Noting (39), (40) and (38),

$$
\left(h_{j}-1\right) h_{j}=\frac{h_{j}}{\varpi} \frac{w_{j} l_{j}}{\psi_{j} x_{j}}=\frac{1}{\varpi} \frac{\beta \lambda \gamma^{\sigma}}{1-\beta} \frac{Z_{j}}{r_{j}}=\frac{1}{\varpi} \frac{\beta \lambda \gamma^{\sigma}}{1-\beta} \frac{1}{\rho / Z_{j}+\left(1-\gamma^{\sigma}\right) \lambda}
$$

obtains. Because $h_{j}>1$, equation (41) defines a function $h_{j}=h\left(Z_{j}\right)>1$ with $h^{\prime}>0$. Inserting this into (40) produces (23).

\section{Appendix B}

We omit subscripts $j$, for convenience. Equations (6) yield

$$
\frac{w}{v}=\left(\frac{\delta}{1-\delta}\right)^{1 / \varepsilon}\left(\frac{n}{m}\right)^{1 / \varepsilon}, \quad \frac{w}{\psi}=\delta^{1 / \varepsilon}\left(\frac{x}{m}\right)^{1 / \varepsilon}
$$

Substituting these into (13) and (23), we obtain

$$
\begin{aligned}
-\frac{N^{\prime}(l+m)}{N(l+m)} & =\frac{w}{v n}=\left(\frac{\delta}{1-\delta}\right)^{1 / \varepsilon}\left(\frac{n}{m}\right)^{1 / \varepsilon} \frac{1}{n}=\left(\frac{\delta}{1-\delta}\right)^{1 / \varepsilon} n^{1 / \varepsilon-1} m^{-1 / \varepsilon}, \\
\varpi[h(Z)-1] & =(l / x) w / \psi=\delta^{1 / \varepsilon} x^{1 / \varepsilon-1} m^{-1 / \varepsilon} l .
\end{aligned}
$$

Taking a logarithm of these and noting (4), we obtain a system of three equations,

$\log \left[-N^{\prime}(l+m)\right]-\log N(l+m)+(1 / \varepsilon) \log m+(1-1 / \varepsilon) \log n=$ constants, $(1 / \varepsilon-1) \log x-(1 / \varepsilon) \log m+\log l-\log [h(Z)-1]=$ constants,

$X(m, n)-x=0$,

with endogenous variables $m, n$ and $x$ and exogenous variables $l$ and $Z$. Given $0<\varepsilon<1$, (6) and (13), the Jacobian of the system (42) is

$$
\begin{aligned}
\mathcal{A} & =\left(1-\frac{1}{\varepsilon}\right) \frac{1}{x}\left[\left(\frac{N^{\prime \prime}}{N^{\prime}}-\frac{N^{\prime}}{N}+\frac{1}{\varepsilon m}\right) X_{n}+\left(\frac{1}{\varepsilon}-1\right) \frac{1}{n} X_{m}-\frac{x}{n m \varepsilon}\right] \\
& =\left(1-\frac{1}{\varepsilon}\right) \frac{1}{x}\left[\left(\frac{N^{\prime \prime}}{N^{\prime}}-\frac{N^{\prime}}{N}+\frac{1}{\varepsilon m}\right) X_{n}+\left(\frac{1}{\varepsilon}-1\right) \frac{1}{n} X_{m}-\frac{X_{m} m+X_{n} n}{n m \varepsilon}\right] \\
& =\left(1-\frac{1}{\varepsilon}\right) \frac{1}{x}\left[\left(\frac{N^{\prime \prime}}{N^{\prime}}-\frac{N^{\prime}}{N}\right) X_{n}-\frac{1}{n} X_{m}\right] \\
& =\left(1-\frac{1}{\varepsilon}\right) \frac{X_{n}}{x}\left[\frac{N^{\prime \prime}}{N^{\prime}}-\frac{N^{\prime}}{N}-\frac{1}{n} \frac{w}{v}\right]=\left(1-\frac{1}{\varepsilon}\right) \frac{X_{n}}{x} \frac{N^{\prime \prime}}{N^{\prime}}<0 .
\end{aligned}
$$


By the comparative statics of the system (42), we obtain

$$
\frac{\partial x}{\partial l}=\frac{1}{\mathcal{A l} l}\left[\frac{X_{n} l}{\varepsilon n}\left(\frac{N^{\prime \prime}}{N^{\prime}}-\frac{N^{\prime}}{N}\right)+\left(\frac{N^{\prime \prime}}{N^{\prime}}-\frac{N^{\prime}}{N}+\frac{1}{\varepsilon m}\right) X_{n}+\left(\frac{1}{\varepsilon}-1\right) \frac{X_{m}}{n}\right]<0 .
$$

\section{Appendix C}

From (9) and (25) it follows that in full employment there is

$$
N\left(l_{j}+m\left(l_{j}, Z_{j}\left(l_{j}, l_{-j}, \mu\right)\right)\right)=N_{j}=n_{j}=n\left(l_{j}, Z_{j}\left(l_{j}, l_{-j}, \mu\right)\right) .
$$

This equation defines the function $l_{j}=l_{j}^{f}\left(l_{-j}, \mu\right)$. Given (5), (6), (8), (9), (24) and (26), the logarithm of the product $\mathcal{U}_{j}^{\alpha} \mathcal{F}_{j}^{1-\alpha}$ takes the form

$$
\begin{aligned}
& \Gamma_{j}\left(l_{j}, l_{-j}, \alpha_{j}, \mu\right) \doteq \alpha_{j} \log \mathcal{U}_{j}+\left(1-\alpha_{j}\right) \log \mathcal{F}_{j} \\
& =\log B_{j}^{0}+\alpha_{j} \log \left(\frac{v_{j} n_{j}}{P_{j} B_{j}}\right)+\left(1-\alpha_{j}\right) \log \left(\frac{\pi_{j}}{P_{j} B_{j}}\right)-\log \left[\varrho+(1-\gamma) \lambda Z_{j}\right] \\
& =\alpha_{j} \log \left(\frac{v_{j} n_{j}}{\psi_{j} x_{j}}\right)+\log \frac{\psi_{j} x_{j}}{P_{j} B_{j}}-\log \left[\varrho+(1-\gamma) \lambda Z_{j}\right]+\Theta \\
& =\alpha_{j} \log \left(\psi_{j} / v_{j}\right)^{\varepsilon-1}+\log x_{j}^{1-\beta}-\log \left[\varrho+(1-\gamma) \lambda Z_{j}\right]+\Theta \\
& =-\alpha_{j} \log \left[\delta\left(w_{j} / v_{j}\right)^{1-\varepsilon}+1-\delta\right]+(1-\beta) \log x_{j}-\log \left[\varrho+(1-\gamma) \lambda Z_{j}\right]+\Theta \\
& =-\alpha_{j} \log \left\{\left[\frac{w\left(l_{j}, Z_{j}\right)}{v\left(l_{j}, Z_{j}\right)}\right]^{1-\varepsilon}+1-\delta\right\}+(1-\beta) \log x\left(l_{j}, Z_{j}\right) \\
& \quad-\log \left[\varrho+(1-\gamma) \lambda Z_{j}\right]+\Theta,
\end{aligned}
$$

where $\Theta$ consists of terms that are independent of $l_{j}$.

Because a logarithm is an increasing transformation, the outcome of bargaining is obtained by maximizing the function (43) by $l_{j}$, subject to (25) and (27), taking $l_{-j}$ as given. The Lagrangean of this problem is given by

$$
\begin{aligned}
\mathcal{L} \doteq \Gamma_{j} & \left(l_{j}, l_{-j}, \alpha_{j}, \mu\right)+\xi\left[N\left(l_{j}+m\left(l_{j}, Z_{j}\right)\right)-n\left(l_{j}, Z_{j}\right)\right] \\
& +\varphi\left[\mathcal{U}_{j}\left(l_{j}, l_{-j}, \alpha_{j}, \mu\right)-\mathcal{U}_{j}\left(\tilde{l}_{j}, l_{-j}, \alpha_{j}, \mu\right)\right] \quad \text { with } \quad Z_{j}=l_{j}^{1-\mu} l_{-j}^{\mu}
\end{aligned}
$$

where multipliers $\xi$ and $\varphi$ satisfy Kuhn-Tucker conditions

$$
\begin{aligned}
& \xi\left[N\left(l_{j}+m\left(l_{j}, Z_{j}\right)\right)-n\left(l_{j}, Z_{j}\right)\right]=0, \quad \xi \geq 0, \\
& \varphi\left[\mathcal{U}_{j}\left(l_{j}, l_{-j}, \alpha_{j}, \mu\right)-\mathcal{U}_{j}\left(\tilde{l}_{j}, l_{-j}, \alpha_{j}, \mu\right)\right]=0, \quad \varphi \geq 0 .
\end{aligned}
$$


The first-order conditions of this maximization are (45) and

$$
\frac{\partial \mathcal{L}}{\partial l_{j}}=\frac{\partial \Gamma_{j}}{\partial l_{j}}+\varphi \frac{\partial \mathcal{U}_{j}}{\partial l_{j}}+\xi \frac{\partial\left(N_{j}-n_{j}\right)}{\partial l_{j}}=0
$$

where

$$
\partial\left(N_{j}-n_{j}\right) / \partial l_{j}=N^{\prime}\left(l_{j}+m_{j}\right)\left[1+\partial m / \partial l_{j}\right]-\partial n / \partial l_{j}
$$

Subresult: $\partial^{2} \Gamma_{j} /\left(\partial l_{j} \partial \alpha_{j}\right)>0$ holds when there is unemployment $N_{j}>n_{j}$.

Assume on the contrary that $\partial^{2} \Gamma_{j} /\left(\partial l_{j} \partial \alpha_{j}\right) \leq 0$ holds. Because $\lim _{\alpha \rightarrow 1} \Gamma_{j}=$ $\log \mathcal{U}_{j}$ by (43), this assumption implies

$$
\frac{1}{\mathcal{U}_{j}} \frac{\partial \mathcal{U}_{j}}{\partial l_{j}}=\frac{\partial \log \mathcal{U}_{j}}{\partial l_{j}}=\left.\frac{\partial \Gamma_{j}}{\partial l_{j}}\right|_{\alpha_{j}=1} \leq\left.\frac{\partial \Gamma_{j}}{\partial l_{j}}\right|_{\alpha_{j}<1} .
$$

To prove $\partial\left(N_{j}-n_{j}\right) / \partial l_{j}<0$, assume on the contrary that

$$
\partial\left(N_{j}-n_{j}\right) / \partial l_{j} \geq 0
$$

This and the full employment constraint (12) yield

$$
l_{j} \geq l_{j}^{f}
$$

Given (45)-(48), we obtain

$$
0 \geq-\xi \frac{\partial\left(N_{j}-n_{j}\right)}{\partial l_{j}}=\left[\frac{\partial \Gamma_{j}}{\partial l_{j}}+\varphi \frac{\partial \mathcal{U}_{j}}{\partial l_{j}}\right]_{l_{j}=l_{j}^{f}} \geq\left.\left(\frac{1}{\mathcal{U}_{j}}+\varphi\right) \frac{\partial \mathcal{U}_{j}}{\partial l_{j}}\right|_{l_{j}=l_{j}^{f}}
$$

and $\left[\partial \mathcal{U}_{j} / \partial l_{j}\right]_{l_{j}=l_{j}^{f}} \leq 0$. This and (49) yield

$$
\left.\mathcal{U}_{j}\left(l_{j}, l_{-j}, \alpha_{j}, \mu\right)\right|_{l_{j}>l_{j}^{f}}<\mathcal{U}_{j}\left(l_{j}^{f}, l_{-j}, \alpha_{j}, \mu\right),
$$

which is in contradiction with (27). So there must be

$$
\partial\left(N_{j}-n_{j}\right) / \partial l_{j}<0
$$

From (50) and and the full employment constraint (12) it follows that

$$
l_{j} \leq l_{j}^{f}
$$


Given (45), (46), (47) and (50), we obtain

$$
0<-\xi \frac{\partial\left(N_{j}-n_{j}\right)}{\partial l_{j}}=\left[\frac{\partial \Gamma_{j}}{\partial l_{j}}+\varphi \frac{\partial \mathcal{U}_{j}}{\partial l_{j}}\right]_{l_{j}=l_{j}^{f}} \leq\left.\left(1+\varphi \mathcal{U}_{j}\right) \frac{\partial \Gamma_{j}}{\partial l_{j}}\right|_{l_{j}=l_{j}^{f}}
$$

and $\left[\partial \Gamma_{j} / \partial l_{j}\right]_{l_{j}=l_{j}^{f}}>0$. This and (51) yield

$$
\left.\Gamma_{j}\left(l_{j}, l_{-j}, \alpha_{j}, \mu\right)\right|_{l_{j}<l_{j}^{f}}<\Gamma_{j}\left(l_{j}^{f}, l_{-j}, \alpha_{j}, \mu\right) .
$$

This means that if the function (43) is maximized by $l_{j}$, then there must be $l_{j}=l_{j}^{f}$ and full employment. Hence, $\partial^{2} \Gamma_{j} /\left(\partial l_{j} \partial \alpha_{j}\right) \leq 0$ cannot hold with unemployment $l_{j} \neq l_{j}^{f}$, and the subresult is proven.

Result (i). Given (5), (43) and the subresult, we obtain

$$
\begin{aligned}
\frac{\partial^{2} \Gamma_{j}}{\partial l_{j} \partial \alpha_{j}} & =\frac{(\varepsilon-1) \delta\left(w_{j} / v_{j}\right)^{-\varepsilon}}{\delta\left(w_{j} / v_{j}\right)^{1-\varepsilon}+1-\delta} \frac{\partial\left(w_{j} / v_{j}\right)}{\partial l_{j}}>0 \text { with } l_{j} \neq l_{j}^{f}, \\
\frac{1}{\mathcal{U}_{j}} \frac{\partial \mathcal{U}_{j}}{\partial l_{j}} & =\frac{\partial \log \mathcal{U}_{j}}{\partial l_{j}}=\left.\frac{\partial \Gamma_{j}}{\partial l_{j}}\right|_{\alpha_{j}=1}>\left.\frac{\partial \Gamma_{j}}{\partial l_{j}}\right|_{\alpha_{j}<1} .
\end{aligned}
$$

To prove $\partial\left(N_{j}-n_{j}\right) / \partial l_{j}>0$, assume on the contrary that

$$
\partial\left(N_{j}-n_{j}\right) / \partial l_{j} \leq 0
$$

holds. This and the employment constraint (12) imply

$$
l_{j} \leq l_{j}^{f}
$$

Given (45), (46), (53) and (54), we obtain

$$
0 \leq-\xi \frac{\partial\left(N_{j}-n_{j}\right)}{\partial l_{j}}=\left[\frac{\partial \Gamma_{j}}{\partial l_{j}}+\varphi \frac{\partial \mathcal{U}_{j}}{\partial l_{j}}\right]_{l_{j}=l_{j}^{f}}<\left.\left(\frac{1}{\mathcal{U}_{j}}+\varphi\right) \frac{\partial \mathcal{U}_{j}}{\partial l_{j}}\right|_{l_{j}=l_{j}^{f}}
$$

and $\left[\partial \mathcal{U}_{j} / \partial l_{j}\right]_{l_{j}=l_{j}^{f}}>0$. This and (55) yield

$$
\left.\mathcal{U}_{j}\left(l_{j}, l_{-j}, \alpha_{j}, \mu\right)\right|_{l_{j}<l_{j}^{f}}<\mathcal{U}_{j}\left(l_{j}^{f}, l_{-j}, \alpha_{j}, \mu\right),
$$

which is in contradiction with (27). Hence, inequality (54) cannot hold and

$$
\partial\left(N_{j}-n_{j}\right) / \partial l_{j}>0
$$


is true. Given (25) and (56), $l_{j}$ cannot be below $l_{j}^{f}\left(l_{-j}, \mu\right)$.

Result (ii). Assume unemployment $N_{j}>n_{j}$ and $l_{j}>l_{j}^{f}$. The union's incentive constraint (27) is then a strict inequality and the first-order conditions (45) and (46) take the form $\partial \Gamma_{j} / \partial l_{j}=0$. Given (52) and the second-order condition $\partial^{2} \Gamma_{j} / \partial l_{j}^{2}<0$, the comparative statics of $\partial \Gamma_{j} / \partial l_{j}=0$ produce

$$
l_{j}=l_{j}^{*}\left(l_{-j}, \alpha_{j}, \mu\right), \quad \frac{\partial l_{j}^{*}}{\partial \alpha_{j}}=-\frac{\partial^{2} \Gamma_{j}}{\partial l_{j}} / \frac{\partial^{2} \Gamma_{j}}{\partial l_{j} \partial \alpha_{j}}>0 .
$$

Results (iii). Now we examine the equilibrium of the world in the case $\alpha_{j}=\alpha$ for all $j$, in which all countries $j \in[0,1]$ are in symmetric position. Given the functions (57), we define a system of equations

$$
\Delta_{j}=l_{j}-l_{j}^{*}\left(l_{-j}, \alpha, \mu\right)=0 \text { for all } j,
$$

with endogenous variables $l_{j}$ for all $j$. Differentiating system (58), we obtain the coefficient matrix $\left(\partial \Delta_{j} / \partial l_{k}\right)$. The reaction function of country $j$ is given by (58). The sufficient conditions for the stability of the equilibrium require that the coefficient matrix $\left(\partial \Delta_{j} / \partial l_{k}\right)$ is subject to diagonal dominance. ${ }^{12}$ Noting (9), (58) and the symmetry over $j$, we obtain the diagonal dominance in the form

$$
0<\frac{\partial \Delta_{j}}{\partial l_{j}} \pm \sum_{k \neq j} \frac{\partial \Delta_{j}}{\partial l_{k}}=1 \pm \frac{\partial l_{j}^{*}}{\partial l_{-j}} \sum_{k \neq j} \frac{\partial l_{-j}}{\partial l_{k}}=(J-1) \frac{\partial l_{j}^{*}}{\partial l_{-j}} \frac{\partial l_{-j}}{\partial l_{k}}=1 \pm \frac{\partial l_{j}^{*}}{\partial l_{-j}} .
$$

This implies $\partial l_{j}^{*} / \partial l_{-j}<1$. Because of symmetry $l_{j}=l_{-j}=l$ obtains, and we can transform relations (57) into $l=l_{j}^{*}(l, \alpha, \mu)$. Differentiating this totally and noting (57) and $\partial l_{j}^{*} / \partial l_{-j}<1$ yield

$$
l_{j}=l(\alpha, \mu) \text { with } \partial l / \partial \alpha=\left(\partial l_{j}^{*} / \partial \alpha_{j}\right) /\left[1-l_{j}^{*} / \partial l_{-j}\right]>0 .
$$

\section{Appendix D}

Assume first that there is unemployment, $l_{j}>l_{j}^{f}\left(l_{-j}, \mu\right)$. Inserting the value function $\Upsilon_{j}(t)=\vartheta c_{j}^{\sigma} \gamma^{\sigma t}$ and $\Upsilon_{j}(t+1) / \Upsilon_{j}(t)=\gamma^{\sigma}$ into the Bellman

\footnotetext{
${ }^{12}$ See, for example, Dixit (1986), p. 117. Here, the diagonal term $\partial \Delta_{j} / \partial l_{j}=1$ is positive so that the sum of each row must be greater than zero.
} 
equation (30) and noting (22) produce

$$
\begin{aligned}
0 & =c_{j}^{\sigma} \gamma^{\sigma t}+\left(\gamma^{\sigma}-1\right) \Upsilon_{j}(t) \lambda Z_{j}-\rho \Upsilon_{j}(t) \\
& =\Upsilon_{j}(t)\left[1 / \vartheta-\rho-\left(1-\gamma^{\sigma}\right) \lambda Z_{j}\right]=\Upsilon_{j}(t)\left[1 / \vartheta-r_{j}\right]
\end{aligned}
$$

and $\vartheta=1 / r_{j}>0$. Given $\vartheta=1 / r_{j}>0,(9),(31), \Upsilon_{j}(t)=\vartheta c_{j}^{\sigma} \gamma^{\sigma t}$ and $\Upsilon_{j}(t+1) / \Upsilon_{j}(t)=\gamma^{\sigma}$, we obtain

$$
\begin{aligned}
\frac{1}{\Upsilon_{j}(t)} \frac{\partial \mathcal{B}_{j}}{\partial l_{j}} & =\frac{\sigma c_{j}^{\sigma-1} \gamma^{\sigma t}}{\Upsilon_{j}(t)}\left[\frac{\partial c_{j}}{\partial l_{j}}+\frac{\partial c_{j}}{\partial Z_{j}} \frac{\partial Z_{j}}{\partial l_{j}}\right]+\lambda\left[\frac{\Upsilon_{j}(t+1)}{\Upsilon_{j}(t)}-1\right] \frac{\partial Z_{j}}{\partial l_{j}} \\
& =\frac{\sigma}{c_{j} \vartheta}\left[\frac{\partial c_{j}}{\partial l_{j}}+\frac{\partial c_{j}}{\partial Z_{j}} \frac{\partial Z_{j}}{\partial l_{j}}\right]+\lambda\left(\gamma^{\sigma}-1\right) \frac{\partial Z_{j}}{\partial l_{j}} \\
& =\frac{\sigma r_{j}}{c_{j}}\left[\frac{\partial c_{j}}{\partial l_{j}}+\frac{\partial c_{j}}{\partial Z_{j}} \frac{\partial Z_{j}}{\partial l_{j}}\right]+\lambda\left(\gamma^{\sigma}-1\right) \frac{\partial Z_{j}}{\partial l_{j}} \\
& =\frac{\sigma r_{j}}{c_{j}} \frac{\partial c_{j}}{\partial l_{j}}+\left[\frac{\sigma r_{j}}{c_{j}} \frac{\partial c_{j}}{\partial Z_{j}}+\lambda\left(\gamma^{\sigma}-1\right)\right] \frac{\partial Z_{j}}{\partial l_{j}} \\
& =\frac{\sigma r_{j}}{c_{j}} \frac{\partial c_{j}}{\partial l_{j}}+(1-\mu)\left[\frac{\sigma r_{j}}{c_{j}} \frac{\partial c_{j}}{\partial Z_{j}}+\lambda\left(\gamma^{\sigma}-1\right)\right]\left(\frac{l_{-j}}{l_{j}}\right)^{\mu} .
\end{aligned}
$$

Given $\gamma^{\sigma}>1$ and (59), the first-order condition $\partial \mathcal{B}_{j} / \partial l_{j}=0$ yields

$$
\frac{\partial c_{j}}{\partial l_{j}}+\frac{\partial c_{j}}{\partial Z_{j}} \frac{\partial Z_{j}}{\partial l_{j}}=\frac{\left(1-\gamma^{\sigma}\right) \lambda c_{j}}{\sigma r_{j}} \frac{\partial Z_{j}}{\partial l_{j}}<0
$$

From (9), (22), (24) and (28) one can see that the functions $x_{j}, c_{j}, r_{j}, \partial c_{j} / \partial Z_{j}$ and $\partial c_{j} / \partial l_{j}$ are independent of $\mu$ for $l_{j}=l_{-j}$. This, (28) and (59) yield

$$
\frac{\partial^{2} \mathcal{B}_{j}}{\partial l_{j} \partial \mu}=-\frac{\sigma r_{j}}{c_{j}} \frac{\partial c_{j}}{\partial Z_{j}}+\lambda\left(1-\gamma^{\sigma}\right)=\frac{1}{1-\mu} \frac{\sigma r_{j}}{c_{j}} \frac{\partial c_{j}}{\partial l_{j}}<0 \text { for } l_{j}=l_{-j} .
$$

Differentiating the first-order condition $\partial \mathcal{B}_{j} / \partial l_{j}=0$ and noting (61) and the second-order condition $\partial^{2} \mathcal{B}_{j} / \partial l_{j}^{2}<0$, we obtain

$$
l_{j}=\min \left[l_{j}^{f}\left(l_{-j}, \mu\right), \hat{l}_{j}\left(l_{-j}, \mu\right)\right], \quad \frac{\partial \hat{l}_{j}}{\partial \mu}=-\frac{\partial^{2} \mathcal{B}_{j}}{\partial l_{j} \partial \mu} / \frac{\partial^{2} \mathcal{B}_{j}}{\partial l_{j}^{2}}<0 \text { for } l_{j}=l_{-j} .
$$

If $\hat{l}_{j}\left(l_{-j}, \mu\right)>l_{j}^{f}\left(l_{-j}, \mu\right)$, there is unemployment.

We examine now the equilibrium of the world. Because of symmetry across $j$, we obtain constant $l_{j}^{f}\left(l_{-j}\right)=l^{f}$ for all $j$. Given the functions (62), we can define a system of equations

$$
\mathcal{A}_{j}=l_{j}-\min \left[l^{f}, \hat{l}_{j}\left(l_{-j}, \mu\right)\right]=0 \text { for all } j,
$$


with endogenous variables $l_{j}$ for all $j$. Differentiating this system, we obtain the coefficient matrix $\left(\partial \mathcal{A}_{j} / \partial l_{k}\right)$. The reaction function of country $j$ is given by (63). The sufficient conditions for the stability of the equilibrium require that the coefficient matrix $\left(\partial \mathcal{A}_{j} / \partial l_{k}\right)$ is subject to diagonal dominance. ${ }^{13}$ Noting (9), (62) and (63), we obtain the diagonal dominance in the form

$$
0<\frac{\partial \mathcal{A}_{j}}{\partial l_{j}} \pm \sum_{k \neq j} \frac{\partial \mathcal{A}_{j}}{\partial l_{k}}=1 \pm \frac{\partial \hat{l}_{j}}{\partial l_{-j}} \sum_{k \neq j} \frac{\partial l_{-j}}{\partial l_{k}}=1 \pm \frac{\partial \hat{l}_{j}}{\partial l_{-j}}
$$

This implies $\partial \hat{l}_{j} / \partial l_{-j}<1$. Because of symmetry $l_{j}=l_{-j}=l$ obtains, we can transform relations $(62)$ into $l=\min \left[l^{f}, \hat{l}_{j}(l, \mu)\right]$. Differentiating this totally and noting (62), we obtain

$$
l_{j}=\min \left[l(\mu), l^{f}\right], \quad d l / d \mu=\left(\partial \hat{l}_{j} / \partial \mu\right) /\left[1-\partial \hat{l}_{j} / \partial l_{-j}\right]<0 .
$$

If $l(\mu)>l^{f}(\mu)$, there is unemployment.

Finally, we examine optimal worldwide regulation. Because in this case the governments behaves as if there were only one government in the world, we let $\mu \rightarrow 0$. Given the symmetry across countries $j$, equations (9) and (22) yield $C_{j}=C, l_{j}=l_{-j}=Z_{j}=Z$ and $r_{j}=r=\rho+\left(1-\gamma^{\sigma}\right) \lambda Z$ for all $j$. Noting $\gamma^{\sigma}>1,(22),(24),(28)$ and (60), we obtain the elasticity of consumption $C$ with respect to the interest rate $r$ as follows:

$$
\begin{aligned}
\eta & \doteq \frac{r}{C} \frac{d C}{d r}=\frac{r}{c} \frac{d c}{d r}=\frac{r}{c} \frac{d c}{d Z} \frac{d Z}{d r}=\frac{r}{c} \frac{1}{\left(1-\gamma^{\sigma}\right) \lambda} \frac{d c}{d Z} \\
& =\frac{r}{c} \frac{1}{\left(1-\gamma^{\sigma}\right) \lambda}\left[\frac{\partial c_{j}}{\partial l_{j}}+\frac{\partial c_{j}}{\partial Z_{j}} \frac{\partial Z_{j}}{\partial l_{j}}\right]>0 .
\end{aligned}
$$

Given this, (9) and $\mu \rightarrow 0$, the partial derivative (59) becomes

$$
\frac{1}{\Upsilon_{j}(t)} \frac{\partial \mathcal{B}_{j}}{\partial l_{j}}=\frac{\sigma r}{c}\left[\frac{\partial c_{j}}{\partial l_{j}}+\frac{\partial c_{j}}{\partial Z_{j}} \frac{\partial Z_{j}}{\partial l_{j}}\right]+\lambda\left(\gamma^{\sigma}-1\right)(1-\mu)=\left(1-\gamma^{\sigma}\right) \lambda[\sigma \eta-1] .
$$

Noting this and $\gamma^{\sigma}>1$, we obtain $\partial \mathcal{B}_{j} / \partial l_{j}>0(<0)$ for $\eta<1 / \sigma(\eta>1 / \sigma)$. According to proposition $1(i i)$, this means that the labour market should be regulated (deregulated) to increase (decrease) $l_{j}=l$ for $\eta<1 / \sigma(\eta>1 / \sigma)$.

\footnotetext{
${ }^{13}$ See footnote 12 .
} 


\section{References:}

Aghion, P. and Howitt, P. (1998). Endogenous Growth Theory. Cambridge (Mass.): MIT Press.

Dixit, A. (1986). Comparative statics for oligopoly. International Economic Review 27, 107-122.

Dixit, A. and Pindyck, K. (1994). Investment under Uncertainty. Princeton: Princeton University Press.

Howitt, P., 2000. Endogenous growth and cross country differences. American Economic Review 90, 829-846.

Jerger, J., 2002. Globalization, wage setting, and the welfare state. Journal of Policy Modelling 24, 1-18.

Palokangas, T. (1996). Endogenous growth and collective bargaining. Journal of Economic Dynamics and Control 20, 925-944.

Palokangas, T. (2000). Labour Unions, Public Policy and Economic Growth. Cambridge (U.K.): Cambridge University Press.

Palokangas, T. (2002). Globalization, labour market regulation, and economic growth with creative destruction. Discussion Paper No. 531, Department of Economics, University of Helsinki.

Romer, P.M. (1990). Endogenous technological change. Journal of Political Economy 98, S71-S102.

Wälde, K. (1999). A model of creative destruction with undiversifiable risk and optimizing households. The Economic Journal 109, C156-C171. 


\section{CESifo Working Paper Series}

699 Campbell Leith and Jim Malley, Estimated General Equilibrium Models for the Evaluation of Monetary Policy in the US and Europe, April 2002

700 Yin-Wong Cheung and Jude Yuen, Effects of U.S. Inflation on Hong Kong and Singapore, April 2002

701 Henry Tulkens, On Cooperation in Musgravian Models of Externalities within a Federation, April 2002

702 Ralph Chami and Gregory D. Hess, For Better or For Worse? State-Level Marital Formation and Risk Sharing, April 2002

703 Fredrik Andersson and Kai A. Konrad, Human Capital Investment and Globalization in Extortionary States, April 2002

704 Antonis Adam and Thomas Moutos, The Political Economy of EU Enlargement: Or, Why Japan is not a Candidate Country?, April 2002

705 Daniel Gros and Carsten Hefeker, Common Monetary Policy with Asymmetric Shocks, April 2002

706 Dirk Kiesewetter and Rainer Niemann, Neutral and Equitable Taxation of Pensions as Capital Income, April 2002

707 Robert S. Chirinko, Corporate Taxation, Capital Formation, and the Substitution Elasticity between Labor and Capital, April 2002

708 Frode Meland and Gaute Torsvik, Structural Adjustment and Endogenous Worker Recall Probabilities, April 2002

709 Rainer Niemann and Caren Sureth, Taxation under Uncertainty - Problems of Dynamic Programming and Contingent Claims Analysis in Real Option Theory, April 2002

710 Thomas Moutos and William Scarth, Technical Change and Unemployment: Policy Responses and Distributional Considerations, April 2002

711 Günther Rehme, (Re-)Distribution of Personal Incomes, Education and Economic Performance Across Countries, April 2002

712 Thorvaldur Gylfason and Gylfi Zoega, Inequality and Economic Growth: Do Natural Resources Matter?, April 2002

713 Wolfgang Leininger, Contests over Public Goods: Evolutionary Stability and the FreeRider Problem, April 2002

714 Ernst Fehr and Armin Falk, Psychological Foundations of Incentives, April 2002 
715 Giorgio Brunello, Maria Laura Parisi, and Daniela Sonedda, Labor Taxes and Wages: Evidence from Italy, May 2002

716 Marta Aloi and Huw Dixon, Entry Dynamics, Capacity Utilisation and Productivity in a Dynamic Open Economy, May 2002

717 Paolo M. Panteghini, Asymmetric Taxation under Incremental and Sequential Investment, May 2002

718 Ben J. Heijdra, Christian Keuschnigg, and Wilhelm Kohler, Eastern Enlargement of the EU: Jobs, Investment and Welfare in Present Member Countries, May 2002

719 Tapio Palokangas, The Political Economy of Collective Bargaining, May 2002

720 Gilles Saint-Paul, Some Evolutionary Foundations for Price Level Rigidity, May 2002

721 Giorgio Brunello and Daniela Sonedda, Labor Tax Progressivity, Wage Determination, and the Relative Wage Effect, May 2002

722 Eric van Damme, The Dutch UMTS-Auction, May 2002

723 Paolo M. Panteghini, Endogenous Timing and the Taxation of Discrete Investment Choices, May 2002

724 Achim Wambach, Collusion in Beauty Contests, May 2002

725 Dominique Demougin and Claude Fluet, Preponderance of Evidence, May 2002

726 Gilles Saint-Paul, Growth Effects of Non Proprietary Innovation, May 2002

727 Subir Bose, Gerhard O. Orosel, and Lise Vesterlund, Optimal Pricing and Endogenous Herding, May 2002

728 Erik Leertouwer and Jakob de Haan, How to Use Indicators for 'Corporatism' in Empirical Applications, May 2002

729 Matthias Wrede, Small States, Large Unitary States and Federations, May 2002

730 Christian Schultz, Transparency and Tacit Collusion in a Differentiated Market, May 2002

731 Volker Grossmann, Income Inequality, Voting Over the Size of Public Consumption, and Growth, May 2002

$732 \mathrm{Yu}-\mathrm{Fu}$ Chen and Michael Funke, Working Time and Employment under Uncertainty, May 2002

733 Kjell Erik Lommerud, Odd Rune Straume, and Lars Sørgard, Downstream Merger with Oligopolistic Input Suppliers, May 2002 
734 Saku Aura, Does the Balance of Power Within a Family Matter? The Case of the Retirement Equity Act, May 2002

735 Sandro Brusco and Fausto Panunzi, Reallocation of Corporate Resources and Managerial Incentives in Internal Capital Markets, May 2002

736 Stefan Napel and Mika Widgrén, Strategic Power Revisited, May 2002

737 Martin W. Cripps, Godfrey Keller, and Sven Rady, Strategic Experimentation: The Case of Poisson Bandits, May 2002

738 Pierre André Chiappori and Bernard Salanié, Testing Contract Theory: A Survey of Some Recent Work, June 2002

739 Robert J. Gary-Bobo and Sophie Larribeau, A Structural Econometric Model of Price Discrimination in the Mortgage Lending Industry, June 2002

740 Laurent Linnemer, When Backward Integration by a Dominant Firm Improves Welfare, June 2002

741 Gebhard Kirchgässner and Friedrich Schneider, On the Political Economy of Environmental Policy, June 2002

742 Christian Keuschnigg and Soren Bo Nielsen, Start-ups, Venture Capitalits, and the Capital Gains Tax, June 2002

743 Robert Fenge, Silke Uebelmesser, and Martin Werding, Second-best Properties of Implicit Social Security Taxes: Theory and Evidence, June 2002

744 Wendell Fleming and Jerome Stein, Stochastic Optimal Control, International Finance and Debt, June 2002

745 Gene M. Grossman, The Distribution of Talent and the Pattern and Consequences of International Trade, June 2002

746 Oleksiy Ivaschenko, Growth and Inequality: Evidence from Transitional Economies, June 2002

747 Burkhard Heer, Should Unemployment Benefits be Related to Previous Earnings?, July 2002

748 Bas van Aarle, Giovanni Di Bartolomeo, Jacob Engwerda, and Joseph Plasmans, Staying Together or Breaking Apart: Policy-makers' Endogenous Coalitions Formation in the European Economic and Monetary Union, July 2002

749 Hans Gersbach, Democratic Mechanisms: Double Majority Rules and Flexible Agenda Costs, July 2002

750 Bruno S. Frey and Stephan Meier, Pro-Social Behavior, Reciprocity or Both?, July 2002

751 Jonas Agell and Helge Bennmarker, Wage Policy and Endogenous Wage Rigidity: A Representative View From the Inside, July 2002 
752 Edward Castronova, On Virtual Economies, July 2002

753 Rebecca M. Blank, U.S. Welfare Reform: What's Relevant for Europe?, July 2002

754 Ruslan Lukach and Joseph Plasmans, Measuring Knowledge Spillovers Using Patent Citations: Evidence from the Belgian Firm's Data, July 2002

755 Aaron Tornell and Frank Westermann, Boom-Bust Cycles in Middle Income Countries: Facts and Explanation, July 2002

756 Jan K. Brueckner, Internalization of Airport Congestion: A Network Analysis, July 2002

757 Lawrence M. Kahn, The Impact of Wage-Setting Institutions on the Incidence of Public Employment in the OECD: 1960-98, July 2002

758 Sijbren Cnossen, Tax Policy in the European Union, August 2002

759 Chandima Mendis, External Shocks and Banking Crises in Developing Countries: Does the Exchange Rate Regime Matter?, August 2002

760 Bruno S. Frey and Lars P. Feld, Deterrence and Morale in Taxation: An Empirical Analysis, August 2002

761 Lars Calmfors and Åsa Johansson, Nominal Wage Flexibility, Wage Indexation and Monetary Union, August 2002

762 Alexander R. W. Robson and Stergios Skaperdas, Costly Enforcement of Property Rights and the Coase Theorem, August 2002

763 Horst Raff, Preferential Trade Agreements and Tax Competition for Foreign Direct Investment, August 2002

764 Alex Cukierman and V. Anton Muscatelli, Do Central Banks have Precautionary Demands for Expansions and for Price Stability? - Theory and Evidence, August 2002

765 Giovanni Peri, Knowledge Flows and Knowledge Externalities, August 2002

766 Daniel Friedman and Nirvikar Singh, Equilibrium Vengeance, August 2002

767 Sam Bucovetsky and Michael Smart, The Efficiency Consequences of Local Revenue Equalization: Tax Competition and Tax Distortions, August 2002

768 Tapio Palokangas, International Labour Market Regulation and Economic Growth with Creative Destruction, August 2002 